\title{
A INTERDISCIPLINARIDADE DA EDUCAÇÃO AMBIENTAL NAS PRÁTICAS EDUCACIONAIS DE UMA ESCOLA DE ENSINO FUNDAMENTAL EM CONTAGEM (MG)
}

\author{
Jeciane Cristina Procópio ${ }^{1}$ \\ Kelly Cristina do Vale ${ }^{2}$ \\ Fernanda de Jesus Costa ${ }^{3}$ \\ Cristiane Freitas de Azevedo Barros ${ }^{4}$
}

Resumo: O estudo avalia como a Educação Ambiental é abordada em uma escola pública de Contagem (MG), com foco na distância entre teoria e prática e nos desafios que gestor e professores enfrentam no que se refere a sua essência interdisciplinar. A pesquisa foi baseada em três etapas: i) análise documental dos currículos e do Plano Político e Pedagógico da escola; ii) aplicação de questionários; iii) avaliação visual da utilização dos espaços físicos escolares para tratar as questões ambientais. Os resultados apontam que a Educação Ambiental é abordada de forma superficial. A falta de capacitação do corpo docente e do gestor para desenvolver trabalhos relacionados a este tema, como determina a legislação, destaca-se como fator complicador.

Palavras-chave: Escola Pública; Currículo; Saber Ambiental.

Abstract: This study evaluates how environmental education is addressed at a public school in Contagem (MG, Brazil), focusing on the distance between theory and practice and the challenges school administrators and teachers face regarding its interdisciplinary essence. This research was based on three stages: i) documental analysis of the curricula and the school's political and pedagogical plan; ii) questionnaire application; iii) visual assessment of the use of school physical spaces to address environmental issues. The results suggest that environmental education is superficially approached. The lack of training of the teaching staff and school administrators on developing projects related to this theme, as determined by the legislation, stands out as a complicating factor.

Keywords: Public School, Curriculum, Environmental Knowledge.

1UEMG. E-mail: jeiciane.procopio@gmail.com, Link para o Lattes: http://lattes.cnpq.br/5858031937918001 2UEMG. E-mail: kellyc.dovale@gmail.com. Link para o Lattes: http://lattes.cnpq.br/6235944385491847 3UEMG. E-mail: fernanda.costa@uemg.br. Link para o Lattes: http://lattes.cnpq.br/9387752688292084 ${ }^{4}$ UEMG E-mail: cristiane.barros@uemg.br. Link para o Lattes: http://lattes.cnpq.br/7564645477069543 


\section{Introdução}

A Educação Ambiental surge com um sentido de mudança de comportamento, visando à redução de problemas socioambientais que afetam a qualidade de vida dos seres vivos e interferem na dinâmica natural do planeta. Conforme a Constituição da República Federativa do Brasil de 1988, artigo 225:

Todos têm direito ao meio ambiente equilibrado, bem de uso comum do povo e essencial à sadia qualidade de vida, impondo-se ao poder público e à coletividade o dever de defendê-lo e preservá-lo para a presente e as futuras gerações (BRASIL, 1988).

Por mais que alguns fatos socioambientais possam parecer isolados, todos estão, de alguma forma, conectados e interrelacionados (LEFF, 2001). E é nesse sentido que a Constituição Federal determina que, para que haja equilíbrio ambiental, é preciso que a sociedade se una em favor da defesa do meio ambiente e sua preservação. Neste contexto, a Educação Ambiental surge como elemento fundamental da gestão pública e vem se destacando nas últimas décadas devido ao aumento dos problemas relacionados à degradação dos ecossistemas.

A inserção da Educação Ambiental nas diferentes fases do ensino configura-se como uma importante ferramenta de transformação social. Os professores participam do processo de construção dos saberes ecológicos, tendo muita responsabilidade na formação de novas subjetividades de seus alunos (CARVALHO, 2004).

Com a Constituição de 1988 e demais políticas estabelecidas para a educação no país, ficam explícitas a atribuição do Estado em elaborar padrões curriculares orientadores de ações educativas do ensino obrigatório, reafirmando os direitos dos cidadãos quanto a melhorias da qualidade do ensino nas escolas brasileiras. Neste cenário de construção social, no ano de 1996, é consolidada a Lei Federal no 9.394 - Lei de Diretrizes e Bases da Educação Nacional (LDBEN) que regulamenta o Sistema Nacional de Ensino. Nesta lei, destaca-se que a educação escolar deve relacionar-se com o mundo de trabalho e prática social. Assim, entende-se que a escola é um local de reprodução de sujeitos atuantes, conscientes de seu papel na sociedade. A LDBEN ressalta a questão da formação cidadã, estabelece o desenvolvimento dos currículos para subsidiar esse processo, mas, não estabelece de forma clara o trabalho do tema ambiental nesse currículo (BRASIL, 1996).

Os Parâmetros Curriculares Nacionais (PCN) surgem em 1997 com o intuito de reformular esse ponto dando atenção à questão ambiental nos currículos escolares. No entanto, estes parâmetros são estabelecidos como documentos orientadores e não reguladores (BRASIL, 1997a). Para subsidiar essa reformulação curricular, foi publicada em 1999 a Política Nacional da 
Educação Ambiental (PNEA), a qual estabelece, em seu artigo 8, parágrafo $3^{\circ}$ inciso IV;

As atividades vinculadas à Política Nacional de Educação Ambiental devem ser desenvolvidas na educação em geral e na educação escolar, por meio das seguintes linhas de atuação inter-relacionadas: $\S 3^{\circ}$ As ações de estudos, pesquisas e experimentações voltar-se-ão para: IV - a busca de alternativas curriculares e metodológicas de capacitação na área ambiental (BRASIL, 1999).

A PNEA menciona ainda a didática curricular do tema, destacando o carácter transversal e interdisciplinar, em seu artigo 10:

A Educação Ambiental será desenvolvida como uma prática educativa integrada, contínua e permanente em todos os níveis e modalidades do ensino formal. § 10 A Educação Ambiental não deve ser implantada como disciplina específica no currículo de ensino (BRASIL, 1999).

Mais recentemente, foi homologado o documento da Base Nacional Comum Curricular (BNCC) para a etapa do Ensino Médio. Este documento foi aprimorado, atendendo todas as etapas da Educação Básica e implementando o disposto na LDBEN, que regulamenta uma base nacional comum para o sistema de Ensino:

A BNCC se fundamenta em princípios éticos, políticos e estéticos para estabelecer os Direitos de Aprendizagem e Desenvolvimento, que devem ser o mote de toda a escolarização básica. Em cada etapa de escolarização Educação Infantil, Ensino Fundamental e Ensino Médio - esses Direitos subsidiam a definição dos objetivos de aprendizagem e desenvolvimento dos componentes curriculares (BRASIL, 2016).

Destaca-se, mais uma vez, que nesta metodologia curricular, assim como na LDBEN, não se observa a questão ambiental de forma clara, interdisciplinar e transversal que a Política Nacional da Educação Ambiental explicita em seus artigos. A nova BNCC aborda a Educação Ambiental de maneira econômica e fragmentada, e percebe-se seu desenvolvimento somente em parágrafos que tratam a própria ciência e suas disciplinas em comum. Esta questão já vem sendo observada, sendo inclusive associada a interesses políticos, conforme destacam Piccinini e Andrade (2017, p.11):

Não acreditamos que a EA foi "esquecida" na Base, ou que os temas socioambientais não tenham interesse educativo 
imediato; pelo contrário, trata-se de escolha política centrada no afastamento crítico da educação das questões próximas ao cotidiano socioambiental das escolas, principalmente públicas.

Desta forma, entende-se que fica a cargo das escolas promoverem o ensino da Educação Ambiental, de acordo com o estabelecido nos PCN's e outras leis pertinentes. As escolas devem ser compreendidas como um espaço de formalização e de aplicação de conceitos formadores, contribuindo para a formação de indivíduos conscientes do seu papel na sociedade e nas questões ambientais e sociais (FRAGOSO, NASCIMENTO, 2018).

Em se tratando de currículo educacional, a transversalidade bem como a interdisciplinaridade devem ser consideradas estratégias didáticas no desenvolvimento de temas sociais, como destacado nos PCNs:

A interdisciplinaridade questiona a segmentação entre os diferentes campos de conhecimento produzida por uma abordagem que não leva em conta a inter-relação e a influência entre eles - questiona a visão compartimentada (disciplinar) da realidade sobre a qual a escola, tal como é conhecida, historicamente se constituiu. Refere-se, portanto, a uma relação entre disciplinas. A transversalidade diz respeito à possibilidade de se estabelecer, na prática educativa, uma relação entre aprender na realidade e da realidade de conhecimentos teoricamente sistematizados (aprender sobre a realidade) e as questões da vida real (aprender na realidade e da realidade) (BRASIL, 1997b).

Assim, dada sua importância para a formação humana, caberia ao município e às instituições educacionais não somente a discussão e o desenvolvimento de programas e ações contínuos de Educação Ambiental, como fazê-los de forma integrada no contexto curricular, envolvendo toda a comunidade acadêmica. Neste sentido, o presente trabalho busca compreender como a Educação Ambiental é abordada em uma escola do munício de Contagem - Minas Gerais, com foco na distância entre teoria e prática e nos desafios que gestores e professores enfrentam no que se refere a sua essência interdisciplinar.

\section{Metodologia}

O trabalho foi realizado em uma escola da Rede Pública Municipal de Contagem, localizada no Bairro Retiro, em região de fragilidade econômica e social. A escola, de grande porte, possui boa estrutura. Tem pátio amplo, quadra bem estruturada e coberta, sala de recursos para atendimento educacional especializado, elevador de acesso ao segundo pavimento, rampas para atendimento de alunos cadeirantes, além de laboratórios de Ciências e de informática, biblioteca e cantina. São atendidos 987 alunos, distribuídos nos 
turnos da manhã (437), tarde (369) e noite (181). São 37 turmas, com 27 a 32 alunos e 44 professores.

Trata-se de uma pesquisa qualitativa realizada em três etapas, sendo a primeira a análise documental. Nesta etapa, foram avaliados os currículos das disciplinas Português, Matemática, História e Artes disponíveis no documento denominado "Matrizes de Referência Curricular - Ensino fundamental" (CONTAGEM, 2010). Este documento é pautado pelo conjunto de Diretrizes Norteadoras da Política Educacional de Contagem, alicerçado na BNCC e tem como objetivo padronizar e estruturar as bases do referencial curricular para a Rede Municipal de Educação de Contagem. Além disso, também foi realizada nesta etapa a leitura analítica do Plano Político e Pedagógico (PPP) da escola. Em ambos os documentos, procurou-se identificar os trechos relacionados à Educação Ambiental e seu caráter interdisciplinar.

A segunda etapa consistiu na aplicação de três questionários semiestruturados: um voltado para a pedagoga da escola, outro, para a equipe de professores e o último direcionado ao público estudantil. O questionário da pedagoga tinha nove questões: (1) tempo de trabalho na escola; (2) Atualmente, a escola apresenta algum projeto Ambiental. Poderia descrevê-lo?; (3) Em média, quantas reuniões pedagógicas acontecem com os professores e com os pais de alunos ao longo do ano?; (4) Das reuniões pedagógicas em que já desenvolveu com os professores e pais de alunos, lembra-se de ter trabalhado questões de ordem ambiental em seus planejamentos? Qual foi o tema? (5) Os professores da sua equipe recebem formação continuada oferecida pela escola? (6) Qual a frequência? (7) Já houve alguma formação que trabalhasse assunto de carácter ambiental? (8) Os professores já receberam orientação sobre como trabalhar a Educação Ambiental de maneira interdisciplinar? (9) Existe material de apoio disponível na escola para este trabalho?

O segundo questionário foi direcionado aos professores que ministram as disciplinas de Português, Matemática, História e Artes. No questionário constavam as mesmas questões apresentadas à pedagoga, com a inclusão de tópicos mais específicos referentes às possíveis abordagens sobre temas ambientais em sala de aula: (10) Já trabalhou algum tema de Educação Ambiental em suas aulas? Qual? (11) Com qual frequência você aborda temas ambientais nas suas aulas? (12) Se você trabalha o assunto em suas aulas, qual método utiliza mais? (Livro didático, filmes, documentários, internet, jogos, músicas e brincadeiras, textos, artigos, revistas, outros); (13) Em uma escala de 0 a 10, como classificaria o conhecimento dos alunos das turmas do $9^{\circ}$ ano em relação aos assuntos ambientais?; (14) Você tem dificuldades em trabalhar temas ambientais nas suas aulas? Em caso responda afirmativo, descreva as principais dificuldades.

O terceiro questionário foi entregue a dez alunos em cada uma das três turmas do nono ano, escolhidos por sorteio através da lista de chamada. Nesse questionário, buscou-se avaliar seus conhecimentos: (1) Atualmente, a escola 
apresenta algum projeto Ambiental. Poderia descrevê-lo?; (2) Os professores falam sobre Meio Ambiente durante as aulas? (3) Com qual frequência? (Frequentemente; às vezes; não falam); (4) Que você se lembre, quais disciplinas já trabalharam temas ambientais durante as aulas? (5) Qual o seu interesse pelo assunto Meio Ambiente? (muito; pouco, nenhum) (6) Você acha que a degradação do meio ambiente pode afetar nossa qualidade de vida? (7) De que maneira? Cite exemplos. (8) O lixo pode causar impactos ambientais, marque a medida que você acha mais correta para reduzir o problema (Reduzir a produção de lixo; Enviar tudo para o aterro sanitário; Reciclar ou Queimar o lixo); (9) Marque a alternativa que defina para você o significado de ações antrópicas (Construir sem degradar; Consumo consciente de recursos naturais; Alterações na natureza do planeta, causadas pelas ações do homem; ou Serviços que a natureza presta ao ser humano); (10) Se você acha que a escola devia falar mais sobre o Meio Ambiente, dê sugestões sobre atividades voltadas para esse assunto na Escola.

A terceira e última etapa consistiu na análise visual do uso da estrutura e do espaço da escola, com foco nas áreas de uso comum dos alunos, professores e servidores, para incentivar a discussão e reflexão sobre temas ambientais.

\section{Resultados e Discussão}

\section{O currículo Escolar}

Os currículos das disciplinas de Artes, Português, Matemática e História do nono ano foram avaliados visando observar o tratamento transversal da Educação Ambiental. Os temas foram divididos em Unidades Temáticas, as quais compreendem subtemas chamados de "Objetos do Conhecimento" e suas "Habilidades", que se referem aos resultados que se espera alcançar ao trabalhá-los. Nos currículos de Artes e Português não foi observada nenhuma referência às questões ambientais. Já no currículo de Matemática e História, foram identificados fragmentos que remetem à temática ambiental. No currículo de História está especificada a seguinte orientação: "Identificar direitos civis, políticos e sociais expressos na Constituição de 1988 e relacioná-los com a noção de cidadania." Na Constituição, a Educação Ambiental é estabelecida como um direito de todo cidadão. Neste sentido, entende-se que esta habilidade a ser alcançada conforme estabelecido no currículo, poderá conter informações referentes a este tema transversal. Em relação ao currículo de Matemática, tem-se o trecho referente item "Habilidade de número 10":

Resolver e elaborar problemas que envolvam relações de proporcionalidade direta e inversa entre duas ou mais grandezas, inclusive escalas, divisão em partes proporcionais e taxa de variação, em contextos socioculturais, ambientais e de outras áreas. 
Desta forma, verifica-se que a Educação Ambiental ainda se encontra focada em disciplinas específicas do currículo escolar. A PNEA, no entanto, estabelece que a Educação Ambiental não deva ser implantada como disciplina específica no currículo de ensino, mas sim, desenvolvida como uma prática educativa integrada, contínua e permanente em todos os níveis e modalidades do ensino formal (BRASIL, 1999). Nesse contexto, uma vez que os currículos orientam os professores na ministração dos conteúdos a serem trabalhados, a orientação explícita sobre a Educação Ambiental e seu caráter transversal nos currículos de referência do ensino torna-se importante na garantia do seu desenvolvimento. Como destaca Carvalho (2012):

$\mathrm{Na}$ escola, organizada sobre a lógica dos saberes disciplinares, o resultado é que, por exemplo, o professor de geografia não toca nos aspectos biológicos da formação de um relevo em estudo; o historiador não considera a influência dos fatores geográficos na compreensão do declínio de uma civilização; o professor de Biologia não recupera processos históricos e sociais que interagem na formação de um ecossistema natural." (CARVALHO, 2012, p.131).

Conforme apontam Mazzarino et al. (2012) um dos entraves à transversalidade da Educação Ambiental são os métodos ainda utilizados no processo educativo, que incluem o quadro negro, giz, salas de aulas fechadas, transmissão de conteúdos via livros didáticos e verificação de aprendizagem. Assim, "vivências que estimulem os sentidos e a produção de novos sentidos para a vida" deveriam ser incorporadas ao currículo de forma a possibilitar que a Educação Ambiental seja sentida na pele, e não apenas no intelecto (MAZZARINO et al., 2012, p. 59).

\section{A Educação Ambiental no Projeto Político Pedagógico da Escola}

O PPP da escola discute a importância do currículo escolar para os processos de ensino e aprendizagem e destaca os desafios para a realização de suas práticas como: o contexto social dos alunos, a necessidade de se afastarem da escola por motivos de trabalho, a falta de participação das famílias na vida escolar dos alunos, e a falta de tempo para interação dos professores na busca do desenvolvimento de projetos que trabalhem métodos para uma educação contextualizada. Pontua-se ainda a dificuldade para a realização de projetos transversais, indicando a biblioteca da escola como protagonista e parceira dos professores no desenvolvimento desses projetos e atividades. Também é ressaltada nesse documento a resistência dos professores a trabalhos interdisciplinares, associada às dificuldades de interações uns com os outros, e a dificuldade dos docentes em trabalharem alguns temas transversais como os multiculturais de gênero e etnia, como transcrito a seguir (p.20): 
Os professores não se apropriam dos conteúdos das disciplinas no mesmo nível em que se apropriam dos conteúdos específicos de suas áreas. Por exemplo, professores de Matemática não se dedicam ao tratamento das questões étnico-raciais na mesma proporção que os professores de história, disciplina cujos professores comumente são associados como responsáveis pelo desenvolvimento de projetos dedicados ao tema.

O documento trata ainda de trabalhos realizados com a Educação de Jovens e Adultos EJA, a importância do atendimento especializado a alunos deficientes, avaliações e indicadores de desempenhos, intervenções pedagógicas e projetos realizados anualmente, como o de Esportes, o Cultural, de Música e Dança e o Literário. Nota-se que a questão ambiental não foi tratada diretamente no documento, somente fragmentos relacionados, mas sem aprofundamento, o que pode ser visto como uma falha no papel da escola para a formação de alunos cidadãos, pois "O projeto político pedagógico de uma Educação Ambiental crítica poderia ser sintetizado na intenção de contribuir para uma mudança de valores e atitudes, formando um sujeito ecológico capaz de identificar e problematizar as questões socioambientais e agir sobre elas". (CARVALHO, 2012, p. 158).

A ausência de abordagem explícita sobre como trabalhar a Educação Ambiental no PPP aponta o desinteresse pelo tema e reflete a prevalência de estratégias pedagógicas que perpetuam a educação disciplinar, voltada somente para transmissão de conhecimento. Esta posição vai de encontro ao proposto por Santana et al. (2018, p. 217):

Devido ao seu caráter transformador, a escola tem importante papel social, e por meio da inserção da EA crítica e emancipatória em seu projeto pedagógico, pode proporcionar aos indivíduos embasamento teórico para uma reflexão sobre a sua condição real no ambiente ao qual está inserido, sendo o educador, um articulador das condições necessárias para o desenvolvimento do cidadão crítico e capaz de agir em situações práticas.

Um PPP "ideal" deveria apresentar a escola em todos os sentidos, visando também orientar os professores sobre a necessidade e estratégias para a incorporação curricular da Educação Ambiental, de modo que recémchegados encontrassem uma cultura de trabalhos interdisciplinares já estabelecida. 


\section{Percepções da comunidade acadêmica}

O trabalho da gestão pedagógica inclui tanto o planejamento das aulas como o acompanhamento dos conteúdos, sendo essencial para a inserção da Educação Ambiental no contexto escolar. No entanto, as percepções da pedagoga em relação à Educação Ambiental na escola se mostraram vagas. Não foi respondida a pergunta referente ao desenvolvimento de projetos que abrangem as questões ambientais na escola e foi informado que as reuniões realizadas com pais de alunos e professores são "muitas". Segundo ela, a questão ambiental é discutida com os professores, mas não descreveu os temas abordados. Foi informado ainda que a escola oferece formação complementar e orientação aos professores sobre como trabalhar a questão, embora não tenha especificado se há material de apoio disponível no estabelecimento.

Os quatro professores participantes desta pesquisa afirmaram não haver projetos ambientais na escola e que ocorrem entre 6 e 10 reuniões anuais com a supervisão pedagógica e entre 1 e 5 reuniões com os pais de alunos, nas quais nenhum deles se lembra de terem sido trabalhados temas ambientais. Dois professores afirmaram receber formação continuada pela escola, e que já foi abordado o tema sustentabilidade em uma delas. Dois afirmaram ter recebido orientações sobre como trabalhar de maneira interdisciplinar, e três afirmaram abordar o assunto em sala, mas de maneira esporádica, com foco nos temas reciclagem e sustentabilidade. Dentre os recursos utilizados, foram destacados textos artigos e revistas, filmes e documentários, internet e jogos. Sobre o conhecimento das turmas em relação ao assunto, somente dois professores responderam apontando nota entre 0 e 5.

As respostas dos professores também apontam para a ausência de uma rotina que viabilize discussões frequentes sobre as questões ambientais em sala de aula, sendo o assunto abordado de maneira superficial e dispersa, conforme o interesse de cada um. Considerando que as questões ambientais são comumente tratadas em aulas de Ciências, Geografia e disciplinas afins, fica subentendido que as ações e projetos relacionados à Educação Ambiental podem enfrentar esta mesma resistência. A dificuldade de gestores e professores implantarem e darem continuidade a projetos relacionados ao meio ambiente parece recorrente e já foi reportada em estudos anteriores (ex. MACHADO et al., 2013; SÁ et al., 2015; ARNALDO e SANTANA, 2018). Como ressaltam Mazzarino et al. (2012, p.55), um dos problemas reside no fato da lógica dos saberes disciplinares ainda ser preponderante em detrimento da perspectiva eco pedagógica, a qual poderia favorecer a abordagem transdisciplinar.

A falta de predisposição dos professores em participarem das atividades interdisciplinares voltadas a questões ambientais foi outro obstáculo encontrado por Machado et al. (2013). A apreciação, valorização do trabalho que está sendo proposto e a percepção de que a Educação Ambiental se trata

de um processo longo e contínuo são fatores importantes para que o professor 
se envolva (MAZZARINO et al., 2012). E, nesse contexto, a formação continuada pode ter papel central:

[...] uma atualização sobre temas ambientais é bastante relevante para aquisição de uma nova visão de mundo, permitindo aos professores potencializar suas habilidades, renovar suas atitudes e redirecionar, (re)significando seus próprios conceitos, saindo assim de uma postura fragmentada e simplista (EVANGELISTA; VITAL, 2013, p. 160).

Nesse cenário, além de prevista na Política Nacional de Educação Ambiental, a formação continuada é uma oportunidade para os professores refletirem sobre a conexão entre os temas sociais e ambientais e, também, um incentivo ao desenvolvimento de atividades direcionadas a "transformações ambientais e sociais necessárias para 0 enfrentamento da crise socioambiental, a partir de suas causas e não somente de suas consequências" (ARNALDO; SANTANA, 2018, p.617). Ainda, é preciso considerar que a dificuldade dos gestores e professores em trabalhar a Educação Ambiental de forma interdisciplinar está associada à formação profissional. Nesse contexto, é preciso que a educação universitária assuma sua responsabilidade na resolução dos problemas ambientais, pois, para que a EA seja aplicada ao ensino formal é preciso que ocorram mudanças na base da formação dos professores, independente da especialidade, de forma a superar a simples memorização de conteúdos e aplicação de técnicas ecológicas (GUIMARÃES; TOMAZELLO, 2003).

Somente seis, dentre os 30 alunos sorteados, responderam ao questionário, indicando falta generalizada de interesse em relação ao tema. Cinco alunos afirmaram que os temas ambientais são tratados em sala de aula, mas de modo heterogêneo em diferentes disciplinas: Ciências (5), Geografia (4), Português (1) e Artes (1). Embora as orientações curriculares do município tenham explicitado diretrizes para a inclusão de temas ambientais nas disciplinas de Matemática e História, elas não foram citadas entre os alunos, bem como Inglês e Educação Física. Quadro semelhante foi observado por Santana et al. (2018) ao avaliarem as ações de Educação Ambiental em duas escolas públicas do estado de Alagoas. Eles perceberam clara separação das discussões sobre meio ambiente entre as disciplinas, ficando a responsabilidade de execução das ações de EA a cargo dos professores de Biologia e Geografia.

Somente dois dos seis alunos afirmaram se interessar muito pelas questões ambientais, embora cinco tenham concordado que a degradação afeta a qualidade de vida dos seres humanos. Vale ressaltar, no entanto, que os exemplos apresentados sugerem uma percepção vaga das questões ambientais, como demonstrado pelas seguintes falas: 
"Pode afetar a qualidade do ar, e da água";

"O ar poluente por causa das sujeiras e a poluição, os lixos na rua, porque os esgotos ficam entupidos, e quando chove causam enchentes nas ruas e pode até prejudicar a gente";

"Sem árvore não tem ar e morremos, sem água a gente morre".

Sobre a melhor maneira de sanar o problema do lixo, nenhum aluno marcou "reduzir a produção", a opção mais apropriada, e, quanto à definição da expressão "Ações Antrópicas" somente um aluno marcou a opção correta ("alteração da natureza do planeta, causadas pelas ações do homem"). Descrições associadas a outros termos ambientais, como "Serviços que a natureza presta ao ser humano" e "Consumo consciente de recursos naturais" foram selecionados por dois alunos.

As respostas dos alunos corroboram que a percepção de que os temas ambientais são tratados de forma superficial na escola. Ao serem questionados se achavam suficiente a maneira como o tema meio ambiente era tratado na escola e convidados a sugerirem atividades voltadas para esse assunto, os alunos levantaram a carência dessas abordagens e indicaram "aulas ao ar livre" e "pegar as comidas da cantina para fazer adubo" para tratar da temática ambiental. A inclusão de abordagens práticas e interdisciplinares no contexto da Educação Ambiental poderia contribuir muito para o esclarecimento desses conceitos, uma vez que facilitam a construção de conhecimento, valores sociais, habilidades e atitudes (DIAS, 2010).

\section{Exploração do espaço físico com abordagens ligadas à Educação Ambiental}

A importância de se explorar o espaço escolar para incorporação de temas ambientais ao cotidiano escolar fica evidente quando se considera que:

A percepção ambiental envolve 0 organismo e 0 ambiente, e é influenciada tanto pelos órgãos dos sentidos - percepção como sensação - como por elaborações mentais oriundas de experiências individuais, associações conceituais e contextos socioculturais - percepção como cognição (HOEFFEL; FADINI, 2007, p.255)

Notou-se que o espaço disponível na escola tem grande potencial para exposição de materiais visuais. A despeito disso, observou-se baixo grau de 
utilização dos espaços comuns: nas áreas do pátio, biblioteca, quadra de esportes, espaço de eventos e corredores das salas de aula, somente um cartaz com um trabalho de musicalização e uma pintura na parede remetendo a crianças livres e felizes em um ambiente de área verde foram registrados, refletindo a ausência de uma cultura de promoção da reflexão acerca das questões ambientais.

$\mathrm{Na}$ área dos bebedouros e refeitório, uma das mais acessadas pelos alunos, o único quadro disponível informa a presença de câmeras de monitoramento da Vigilância Patrimonial. Nesse espaço também tinham dois conjuntos de lixeiras para separação de material reciclável seco, um na entrada principal e o outro próximo aos bebedouros. Apesar de ser um ponto de partida para a discussão sobre os temas como resíduos sólidos e consumo consciente, a oportunidade parece não ser explorada, haja vista as respostas dos alunos.

A escola conta com uma ampla área verde, limpa periodicamente, mas não é utilizada para nenhuma atividade e há restrição de acesso pelos alunos. Intervenções coletivas nesse espaço, como o planejamento, organização e manutenção de uma horta, como sugerem os próprios alunos, poderiam atuar como temas geradores do ponto de vista da pedagogia freireana (TOZONIREIS, 2006), os quais podem ser desdobrados pelos professores em subtemas e gerarem tarefas a serem cumpridas dentro das diferentes disciplinas.

Da forma como vem sendo considerada, a Educação Ambiental é tratada na escola ainda de maneira incipiente e com características essencialmente informativas. É necessária a preparação tanto dos gestores quanto dos docentes para sua adaptação ao caráter formativo, voltado para construção de hábitos, atitudes e comportamentos (MAZZARINO et al., 2012).

\section{Considerações finais}

Apesar de ser discutida no Brasil há mais de quatro décadas, a inclusão da Educação Ambiental na escola avaliada ainda não se encontra bem estabelecida. A escola se apresenta como um local de formação, de transformação, devendo receber atenção quanto a sua atuação, seus desafios e obstáculos. Percebe-se que o dia a dia na escola analisada está voltado para a alfabetização, para leitura, para cultura de esportes, dança, artes, e outras questões importantes para o desenvolvimento social de um indivíduo. A Educação Ambiental, no entanto, acaba não recebendo o devido destaque por parte dos docentes e alunos, que sequer percebem a carência e importância dos temas ambientais.

O desenvolvimento da Educação Ambiental nas escolas é um processo longo e contínuo, e deve envolver também a família e a comunidade (MAZZARINO et al., 2012). Nesse percurso, devem estar incluídas estratégias de formação e atualização contínuas dos docentes, uma vez que "é preciso que o educador tenha uma formação emancipadora para que ele possa formar sujeitos críticos, que interpretem e modifiquem a realidade" (DALL'AGNOL; 
AGUIAR, 2018, p. 129). Além do caráter emancipador, também é preciso orientar os professores sobre as formas de se trabalhar o tema de maneira interdisciplinar, fazendo-se necessária também a revisão do PPP da escola no sentido de sensibilizar o corpo docente para a implementação de projetos e ações no âmbito da Educação Ambiental (EVANGELISTA; VITAL, 2013).

Os resultados do diagnóstico foram apresentados aos gestores da escola, acompanhado de propostas para viabilizar maior destaque e envolvimento com os temas ambientais, como a utilização da infraestrutura já disponível para a divulgação e incentivo a reflexão sobre os temas ambientais, maior aproveitamento da área verde, através da criação e manutenção de uma horta e da construção de composteira para os resíduos orgânicos da cozinha. Tal projeto tem potencial para envolver alunos e professores das diferentes disciplinas, de modo a fomentar discussões dentro e fora das salas de aula que fortaleçam a relação entre atividades pedagógicas e o desenvolvimento de percepções ambientais mais críticas e conscientes.

\section{Agradecimentos}

Agradecemos à diretoria da escola pela autorização e suporte durante o desenvolvimento da pesquisa, à coordenação pedagógica, professores e alunos participantes e à Silvana Matos pela revisão do texto.

\section{Referências}

ARNALDO, M.A.; SANTANA, L.C. Políticas públicas de Educação Ambiental e processos de mediação em escolas de Ensino Fundamental. Ciência \& Educação, v. 24, n. 3, p. 599-619, 2018.

BRASIL. Constituição da República Federativa do Brasil. 1988. Disponível em:<http://www.planalto.gov.br/ccivil 03/constituicao/constituicaocompilado.ht m>. Acesso em: 29 jul. 2019.

BRASIL. Secretaria de Educação Fundamental. Parâmetros Curriculares Nacionais: introdução aos parâmetros curriculares nacionais / Secretaria de Educação Fundamental. - Brasília: MEC/SEF, 1997a. Disponível em: http://portal.mec.gov.br/par/195-secretarias-112877938/seb-educacao-basica2007048997/12640-parametros-curriculares-nacionais-10-a-4o-series. Acesso em 22 ago. 2019.

BRASIL. Secretaria de Educação Fundamental. Parâmetros Curriculares Nacionais: Temas Transversais - Apresentação - Volume 08.1 / Secretaria de Educação Fundamental. - Brasília: MEC/SEF, 1997b. Disponível em: http://portal.mec.gov.br/par/195-secretarias-112877938/seb-educacao-basica2007048997/12640-parametros-curriculares-nacionais-10-a-4o-series.\%20. Acesso em: 22 ago. 2019. 
BRASIL. Lei N 9.795, de 27 de abril de 1999. Política Nacional de Educação Ambiental PNEA.

Disponível em https://www.planalto.gov.br/ccivil 03/leis/l9795.htm Acesso em: 22 ago. 2019.

BRASIL. Lei № 9.394, de 20 de dezembro de 1996. Diretrizes E Bases Da Educação Nacional - LDBEN - Disponível em https://www.planalto.gov.br/ccivil 03/leis/l9394.htm Acesso em: 22 ago. 2019.

BRASIL. Ministério da Educação e Cultura. Base Nacional Comum Curricular - BNCC. Disponível em: http://basenacionalcomum.mec.gov.br/images/BNCC El EF 110518 versaofin al site.pdf. Acesso em: 25 ago. 2019.

DALL'AGNOL, M.; AGUIAR, D. R. C. A Práxis Pedagógica no Ensino da Educação Ambiental Crítica Em Uma Escola da Rede Pública Municipal De Ensino De Porto Nacional (TO). Revista Brasileira de Educação Ambiental, v. 13, n. 4, p. 126-145, 2018.

DIAS, G. F. Educação Ambiental: princípios e práticas. 9. Ed. São Paulo: Editora Gaia, 2010.

CARVALHO, I. C. M. Educação Ambiental Crítica: nomes e endereçamentos da educação In: LAYRARGUES, P. P. (Org.) Identidades da Educação Ambiental Brasileira. Brasília: Ministério do Meio Ambiente, 2004.

CARVALHO, I. C. M. Educação Ambiental: a formação do sujeito ecológico. 6. Ed. São Paulo: Cortez, 2012.

CONTAGEM. Secretaria Municipal de Educação e Cultura. Matrizes de Referência Curricular - Ensino fundamental. Contagem, Minas Gerais, 2010.

EVANGELISTA, M. A. A.; VITAL, A. F. M. Visão dos Professores da rede pública estadual de Sumé (PB) sobre as dificuldades na condução de ações em Educação Ambiental. Revista Brasileira de Educação Ambiental, v. 8, n. 2, p. 150-163, 2013.

FRAGOSO, E.; NASCIMENTO, E.C.M. A Educação Ambiental no ensino e na prática da Escola Estadual Cândido Mariano - Aquidauana/MS. Ambiente e Educação, v. 23, n. 1, p. 161-184, 2018.

GUIMARÃES, S.S.M.; TOMAZELLO, M.G.C. A formação universitária para o ambiente: educação para a sustentabilidade. Ambiente e Educação, v. 8, n. 1, p. 55-71, 2003.

HOEFFEL, J. L.; FADINI, A.A.B. Percepção ambiental. In: FERRARO JUNIOR, L. A. (Org.). Encontros e Caminhos: formação de educadoras(es) ambientais e coletivos educadores. Vol 2. Brasília: MMA, Diretoria de Educação Ambiental, 2007. p. 253-262.

LEFF, E. Saber ambiental: sustentabilidade, racionalidade, complexidade, poder. Petrópolis: Vozes, 2001. 
MACHADO, M.M. et al. Educação Ambiental na escola pública Unidade Integrada Governador Matos Carvalho, São Luís (MA): um estudo de caso. Revista Brasileira de Educação Ambiental, v. 8, n. 2, p. 20-30, 2013.

MAZZARINO, J.M. et al. Currículo, Transversalidade e Sentidos em Educação Ambiental. Revista Brasileira de Educação Ambiental, v. 7, n. 2, p. 51-61, 2012.

PICCININI, C.L.; ANDRADE, M.C.P. Educação Ambiental na Base Nacional Comum Curricular: retrocessos, contradições e o apagamento do debate socioambiental. Anais do VIII Encontro Regional de Ensino de Biologia RJ/ES, 2017. Anais...Rio de Janeiro, RJ: UNIRIO - UFRJ - IBC, 2017. Disponível em: http://www.colemarx.com.br/wpcontent/uploads/2018/03/EDUCA\%C3\%87\%C3 $\% 830$-AMBIENTAL-NA-BASE-NACIONAL-COMUM-CURRICULAR RETROCESSOS CONTRADI\%C3\%87\%C3\%95ES-E-O-APAGAMENTO-DODEBATE-SOCIOAMBIENTAL.pdf Acesso em 25 ago. 2019.

SÁ, M.A. et al. A importância da Educação Ambiental para o ensino médio. Revista Brasileira de Educação Ambiental, v. 10, n. 3, p. 60-68, 2015.

SANTANA, G.R.A. et al. Análise da inserção da Educação Ambiental nas escolas estaduais da Região Central da Área de Proteção Ambiental Costa Dos Corais (AL). Revista Brasileira de Educação Ambiental, v. 13, n. 4, p. 216227, 2018.

TOZONI-REIS, M.F.C. Temas ambientais como temas geradores para uma metodologia educativa ambiental crítica, transformadora e emancipatória. Educar, n. 27, p. 93-110, 2006. 